Susan D. Phillips ${ }^{1}$

\title{
Putting Humpty Together Again: How Reputation Regulation Fails the Charitable Sector
}

\author{
${ }^{1}$ School of Public Policy and Administratio, Carleton University, 1125 Colonel By Drive, Ottawa, Ontario K1S5B6, Canada, E-mail: \\ susan.phillips@carleton.ca
}

\begin{abstract}
:
Investigations of how Oxfam Great Britain (GB) managed its safeguarding systems and handled revelations of sexual exploitation by its staff highlighted a variety of internal governance and culture issues, and a lack of transparency as it sought to protect its reputation. The current models of reputation management do not fully explain its actions, however. This article argues that five systemic factors in the environment in which nonprofits operate create undue pressures for protection of reputations and contribute to poor assessment of risks, inadequate accountability systems and limited transparency. These factors include: a stress on success and related competition for market share and pressures for growth; expectations of low overheads; challenges of governance and risk management; lack of public awareness; and regulatory gaps. Drawing on media coverage and the commissions of inquiry, the analysis shows how all of these contextual factors were at play in the Oxfam case, and suggests potential reforms.
\end{abstract}

Keywords: reputation management, Oxfam scandal, nonprofit policy, charity regulation, self-regulation DOI: 10.1515/npf-2019-0032

Oxfam Great Britain (GB) became the epicentre of a crisis in early 2018 when news broke that several of its employees delivering humanitarian aid in Haiti following the 2010 earthquake had been dismissed for sexual exploitation of local women and for bullying and intimidation. Reports of sexual abuse and misconduct soon surfaced in other highly respected international NGOs (INGOs), including Save the Children, Médecins Sans Frontières and Amnesty International. Oxfam was not alone: it just happened to be "holding the bomb went it went off" (Cooney 2019b). Operating as part of a global confederation of 19 affiliates, whose work is coordinated through Oxfam International based in the Netherlands, Oxfam GB is a separate legal entity, governed by its own trustees, and as a registered charity is under the regulatory authority of the Charity Commission for England and Wales. ${ }^{1}$ The inquiry conducted by the Charity Commission (CCEW 2019a) on how Oxfam GB handled the incident and managed its safeguarding mechanisms concluded that there were structural weaknesses and inadequate resourcing of its quality assurance and accountability systems - although these were widely regarded as being among the best of any INGO (Mazurana and Donnelly 2017) ${ }^{2}$ In addition, its trustees and executives did not exercise adequate oversight relative to risks, and it allowed an internal culture to exist that tolerated bad behavior. While there was no intentional cover-up, it avoided "full and frank" reporting to the regulator, funders and the public (CCEW 2019a, 74). Indeed, the inquiry (CCEW 2019b, 1) clearly implied that, through its lack of transparency, Oxfam GB put protecting its reputation and donor relationships in the short term above protecting those it serves or maintaining public trust over the longer term.

The problems inherent in the current system of nonprofit reputation management are not specific to Oxfam or to INGOs, and these deeper issues - which were ignored in the Charity Commission's report - will not be fixed by individual organizations. Rather, they reflect certain systemic aspects of the environment in which nonprofits, of all types and sizes, operate that put unduly strong pressures on protection of organizational reputations while encouraging inadequate risk management and limited transparency. Unless these entrenched, systemic issues are addressed, we can expect repeated incidents of poor behavior. My research quest is to better understand how certain contextual factors influence reputation management by nonprofits. I argue that five systemic factors create a damaging environment for nonprofit reputation management: a stress on success and related competition for market share and pressures for growth; expectations of low overheads; challenges of governance and risk management; lack of public awareness; and regulatory gaps. This analysis considers the extent to which each of these contextual factors were at play in the Oxfam case. 
While global INGOs such as Oxfam are distinctive creatures in the nonprofit sector, organized as complex confederations of country-based affiliates and operating under difficult conditions in delivering humanitarian aid (Deloffre and Schmitz 2019), the system failures addressed in this article apply to many different types of charities, international and domestic, large and small. As the Chair of the Charity Commission prefaced the inquiry's report, "no charity is too small to bear its own share of responsibility for upholding the wider good name of charity" (CCEW 2019b, 1). How do we put a broken system of reputation management back together? The conclusion offers some suggestions for improvements so as to mitigate the negative incentives of the current system. Before addressing these systemic issues, I begin by outlining the theory of reputation regulation (Busuioc and Lodge 2016, 2017; Christensen and Lodge 2018) and its application to nonprofits.

\section{Reputation Management and Regulation in Theory}

A reputational approach to regulation assumes that organizations are motivated primarily by protecting and elevating their reputations, which are embedded in a network of multiple audiences and in a variety of regulatory relationships with the state, third parties and self-regulation (Carpenter and Krause 2012; Maor, Gilad, and Bloom 2013; Busuioc and Lodge 2017; Mitchell and Stroup 2017; Christensen and Lodge 2018; Crack 2018). Organizational reputation is a set of beliefs, perceptions and collective evaluations by various stakeholders about an organization's visibility, capabilities or its character, and can be positive or negative (Lange, Lee, and Dai 2011; Carpenter and Krause 2012; Mishina, Block, and Mannor 2012). Organizations may adhere to formal rules and standards, albeit often in a minimalist way, but they also internalize the expectations of different audiences, which become their own norms. As Busuioc and Lodge $(2017,99)$ argue, "organizations selectively focus their activities and responses on some responsibilities more than others," and when reputation matters deeply to an organization, the assumption is that it will voluntarily undertake enhanced levels of transparency and accountability, going beyond what established rules require, and when not salient, it will likely provide a bare minimum of attention or compliance.

Reputational concerns are argued to be particularly important for nonprofits because, as Mitchell and Stroup (2017) note, their power derives from their ability to influence which is dependent on their perceived credibility, and in an information scarce environment reputation becomes a proxy for effectiveness. A popular means of enhancing reputation is to become part of an "accountability club" - a voluntary code or certification mechanism (Prakash and Potoski 2007; Prakash and Gugerty 2010; Potoski and Prakash 2013). The trustmark that accompanies membership in a club is a shorthand signal of quality that enhances their 'brand,' while the robustness of the standards and monitoring practices of the accountability club contribute to its legitimacy (Prakash and Potoski 2007; Gugerty 2009). The nature and rigor of these mechanisms vary widely, however, and evidence on their value in signaling virtue is mixed (Gugerty 2009; Willems et al. 2017; Becker 2018). While there is an indication that certification systems involving substantial self- and peer assessment and ongoing monitoring enhance public trust and intention to donate (Bekkers 2003; Feng, Neely, and Slatten 2016; Becker 2018; Peng, Kim, and Deat 2019), the effectiveness of clubs requiring only self-proclaimed adherence to standards is generally assessed to be weak (Gugerty 2009; Tremblay-Boire, Prakash, and Gugerty 2016). Third party watchdogs, such as Charity Navigator and GuideStar (now Candid), among many others, claim to overcome the disclosure deficit of self-regulation by providing independent assessments and ratings, again with the assumption that nonprofits will strive to achieve higher ratings and that such ratings will be used by potential supporters to make informed decisions about giving and volunteering.

Transparency is essential to all of these regulation-by-reputation processes and to bringing about improved performance. The supposed causal chain is, first, that the information disclosed is salient to the audience and, second, these users act on this information (Fung, Graham, and Weil 2007). To actually improve the performance of a nonprofit, this information needs to be "doubly embedded:" the organization needs to be attuned to the users' perceptions and actions so that their responses affect the disclosers' decision calculations and behavior (Weil et al. 2005, 158). When transparency satisfies audience expectations it has been shown to enhance public trust in nonprofits, which results in increased donations and other supportive behaviors (Sargeant and Lee 2004; Sarstedt and Schloderer 2010; Auger 2014; Willems, Boenigk, and Jegers 2014; Farwell, Shier, and Handy 2019). As Willems, Jegers and Faulk $(2016,468)$ report, when stakeholders are satisfied with the quality of a nonprofit's communication with them, it has a direct positive effect on their perceptions of its effectiveness and, when accumulated over time, has an indirect enduring impact by raising their general "stock" of trust in the organization and the sector as a whole.

In times of crisis, voluntary disclosure is argued to be particularly important for reputation maintenance. Aside from the normative case that full disclosure is the ethical thing to do to protect those affected by a crisis (Coombs 2007), the strategic communications literature provides consistent advice that a rapid response with 
full information is prudent in mitigating reputational damage in the short run and maintaining stakeholder trust (Pfarrer et al. 2008; Cordery and Baskerville 2011; Harris and Neely 2018). Indeed, Arpan and RoskosEwoldsen (2005) suggest that an even more assertive strategy of "stealing thunder" by voluntarily disclosing potentially damaging information before it is released by a third party or the media can enhance an organization's credibility and reduce perceptions of the severity of a crisis.

This potentially virtuous cycle of reputation management via transparency can break down for several reasons. First, nonprofits may not be as likely to voluntary disclose information, including during crises, as the model predicts. A number of recent studies have revealed very limited degrees of voluntary disclosure by nonprofits, including by - in fact, less likely by - large ones (Saxton, Kuo, and Ho 2012; Bond 2014; Tremblay-Boire and Prakash 2015; Hyndman and McConville 2016). The key factors in being more transparent seem to be strong governance and professionalism, rather than size alone or external pressures (Striebing 2017; Harris, Petrovits, and Yetman 2018). As McDonnell and Rutherford (2018) note, the "early adopters" in reporting serious incidents to the Scottish charity regulator appear not only to recognize they may be at risk of such incidents, but they have the requisite governance systems to be accountable, and thus may be using such reporting as a means of signalling to the regulator their concern with good governance.

A related shortcoming is that, when information is provided, it may be unduly shallow (Schleifer, Fiorini, and Auld 2019) or "opaque" (Fox 2007), for instance limited to superficial information about formal procedures for safeguarding, rather than being deeper, more detailed - and thus more sensitive - information about the actual practices of safeguarding and what worked (or went wrong). The concern of a shortfall in the quality of information applies not only to individual nonprofits, but to self-regulation mechanisms which Schleifer, Fiorini and Auld $(2019,16)$ argue disclose too little information to make "the transparency action cycle swing." The problem of quality information can be both improved and inhibited by mandatory public reporting. As Brody (2012) observes, sunlight can produce shadows as well as clarity, and in requiring certain types of information, the onus is on regulators to ensure they are asking for the "right" kinds of relevant information.

The reputation regulation loop also stalls at the next stage: the need for users to seek out, effectively process and act on the information. Such faltering is demonstrated by the mixed evidence on the extent to which watchdog ratings are used in donor decision making (Mitchell 2014). While a positive relationship between a change in ratings and contributions is found by Gordon, Knock, and Neely (2009) and a slight effect of positive ratings on donations, but with no effect of bad ratings by Sloan (2009), no effects of either good or poor ratings on donor behavior or on how nonprofits report information are indicated by Szper and Prakash (2011). Further, Cnaan et al. (2011) show that most donors do not bother to consult the ratings at all when making their decisions. Similarly, in contesting the general finding from studies of the corporate sector that voluntary disclosure following a crisis will prevent loss of trust, Willems and Faulk (2019) observe that such disclosure has no effect, at least in the short term, perhaps due to information asymmetries and the subjective nature of nonprofit performance.

A final complication is that reputations tend to be path dependent and durable, particularly for large organizations (Mishina, Block, and Mannor 2012; Mitchell and Stroup 2017; Archambeault and Webber 2018; Scurlock, Dolsak, and Prakash 2019), and the formation and influence of trust is not as linear and rational as most models of reputation regulation presume. Social trust based on shared social identities and cause-based solidarities often predisposes people to have affinities for particular nonprofits without much of an evidentiary base (Rousseau et al. 1998; Keating and Thrandardottir 2017). Rather than being informed, strategic decision makers, people act as "motivated reasoners:" they establish warm glows about certain brands early on, then seek out congenial information about their brand, perhaps ignoring contrary information. In effect, their trust becomes habitual. A reputation for character, as distinct from capability, depends on a regular feed of positive cues, and thus takes time to build, but once established becomes easier to maintain and enhance. This gives those that have had a positive light early on and remained visible - which are often the largest nonprofits - a sustained competitive advantage (Mishina, Block, and Mannor 2012; Mitchell and Stroup 2017; Archambeault and Webber 2018).

Reputation management research features a thriving diversity of studies, particularly through experimental designs, to test responses to crises, stickiness of reputations and effects of disclosure. Many of these studies, however, test reputational signals in a rather "pure" form - how ratings are presented (Willlems, Waldner, and Ronquillo 2019), for example, and the effects of financial efficiency or accreditation on reputation (Peng, Kim, and Deat 2019). My argument is that existing models of reputation management alone cannot fully explain behavior in the Oxfam GB and related misconduct cases because the environment in which nonprofits operate has become complicated by a number of systemic factors that distort their actions in favour of excessive reputational protection and contribute to poor assessment of risks, inadequate accountability systems and lack of transparency. 


\section{The Contemporary Nonprofit Environment: Negative Influences on Reputation Management}

The Oxfam GB case illustrates the implications of a combination of dysfunctional aspects of the nonprofit environment, each of which have been identified in the existing research and practice literature but are often considered in isolation, rather than as a composite. This analysis explores the effects of five factors, using an analysis of the media coverage and commentaries as well the reports of the parliamentary committee (House of Commons, International Development Committee, UK 2018), independent commission established by Oxfam International (Independent Commission on Sexual Misconduct, Accountability and Culture Change 2019), and Charity Commission (2019a) to assess the saliency of each in this case. ${ }^{3}$

\subsection{Competition for Success}

In recent years, concerns over accountability for results has been incorporated into regulatory systems in both hard and soft ways, particularly in the types of information mandated or expected. Achieving measurable impacts is embedded in philanthropy, big and small, and a common theme in surveys of donors is that they expect charities to demonstrate their (positive) results (Bagwell et al. 2013; Muttart Foundation 2013; Populus and Charity Commission 2018). Governments and foundations have also fixated on accountability for results and value for money, building detailed performance indicators into their grants and contracts (Bond 2012; Barnett 2016). The stress on success is compounded by a competitive funding and contracting environment, particularly when nonprofits are competing for large amounts from a few players of scale, as occurs in international aid (Barnett 2016; Berghmans, Simons, and Vandenabeele 2017; Bush 2015; Crack 2016).

Designing gifts, grants and contracts with impact in mind is not inherently a bad thing if we want to achieve significant social change. Taken to the extreme, however, the consequences are that means become secondary to results, short-term effects get more attention than efforts to achieve lasting change and it is difficult to admit failure, particularly if future support from a government, foundation or venture philanthropist is dependent on success (Crack 2016; Mitchell 2015). ${ }^{4}$ It also puts a premium on size and continued growth so as to attain more and larger contracts or grants, which then becomes a reinforcing cycle in order to support a bigger infrastructure. The drive for growth and 'success' can easily enable a toxic work environment to develop and fester, as was reported by many staff of Oxfam and other INGOs (Independent Commission on Sexual Misconduct, Accountability and Culture Change 2019). ${ }^{5}$ In evidence to a parliamentary committee, the staff member who oversaw safeguarding at Oxfam GB reflected on its preoccupation with "brand penetration," commenting that "I have little doubt that in Oxfam's haste to 'increase its market share,' it also increased the probability of vulnerable recipients being exposed to abuse by staff who were ill-prepared, poorly vetted and badly managed" (Anderson 2018).

The fear of failure also applies to major funders and donors who have staked their own reputations on results. In this case, two of the major funders (and the regulator) apparently knew at least the basics of the wrongdoing soon after the incident, they did not disclose this or push for a public investigation.

\subsection{Pressures for Low Overheads}

The notion that the effectiveness and efficiency of nonprofits is indicated by low expenditures on administration has been advanced by third party rating agencies, and limits on these costs have been embedded in government contracts, foundation funding and public perceptions (Gneezy, Keenan, and Gneezy 2014; Meer 2017), even though an overhead ratio is not a good measure of either efficiency or effectiveness (Coupet and Berrett 2019). Although in 2014 the leading US third party watchdogs supported a campaign to dispel the 'overhead myth,' the desirability of minimal overheads remains lodged in public opinion: indeed, surveys show that low administrative costs and overall financial transparency are more important considerations in the willingness to give than is demonstrated success (Harold 2014; Grey Matter Research 2018; Populus and Charity Commission 2018). In response to public expectations, nonprofits have reduced their spending on overheads, producing a "starvation cycle" of under investment in infrastructure and reductions in staff expenses and fundraising costs (Gregory and Howard 2009; Hager et al. 2004; Lecy and Searing 2015; Schubert and Boenigk 2019).

Even a large organization such as Oxfam responds to these pressures, prominently displaying the percentages of its revenues spent on overheads $-7 \%$ on fundraising and $10 \%$ on administration, control and compliance costs (Oxfam 2018). Oxfam's chair confirmed that pressures to keep overheads low was a consideration in how it resourced its accountability systems (Weakley 2018) and, as one of its human resources staff told 
the Independent Commission $(2019,22)$, this pressure had direct implications for safeguarding practices: "We manage safeguarding on top of our normal responsibilities, so it never receives the attention it deserves." In addition to limiting funds for internal control systems, the expectations of low administrative costs diminish resources available for managing relationships with the grassroots (Bryant 2007; Crack 2018). Although Oxfam has a philosophy of local empowerment and has been perceived as better than most in its participatory approach, the Independent Commission $(2019,20)$ nevertheless noted that power relationships and inadequate attention to stakeholder relations often silence local peoples. It affirmed that "there is a real need for Oxfam staff - particularly its leadership - to examine if and how they understand and exemplify feminist principles and Oxfam's values of empowerment, accountability, and inclusiveness." Unfortunately, in a value for money context, the reputation with major funders for perceived efficiency can readily gain primacy over the reputation at the grassroots for inclusive engagement.

\subsection{Challenges of Covernance and Risk Management}

The need for more sophisticated safeguarding and related systems, as well as preventing toxic work cultures, places an additional onus on boards of directors - and illuminates some of the current shortcomings of organizational governance that appear to be widely experienced across the sector. In a large, complex organization such as Oxfam GB, it is natural that the trustees would rely on extensive delegation of operational decisionmaking to the executive and staff. As the Charity Commission (2019a) noted, however, such delegation means that trustees must still exercise effective oversight in order to meet their fiduciary and legal duties through appropriate assurance and audit systems and adequate reporting by the executive. In this case, the oversight and scrutiny of the executive was found to be inadequate, and a culture existed that did not empower staff to challenge them. ${ }^{6}$ The Commission was emphatic that the exercise of trusteeship requires more than policies and procedures: rather trustees need to "actively understand the risks to their charity and make sure those risks are properly managed," and that maintaining an inclusive culture needs to be "embedded through the day-to-day actions" and modelled from the top down.

A systemic factor that contributes to weaknesses in governance and risk management is a lack of diversity and inclusion on nonprofit boards. As Fredette and Bernstein (2019) demonstrate, a critical mass of racial/ethnic diversity improves performance, including fiduciary performance and stakeholder engagement, and genuine inclusiveness creates greater opportunities to motivate change. In spite of the rhetoric about the need to better reflect and meaningfully engage diverse populations and youth, a lack of nonprofit board diversity persists across most high income countries (Weisinger et al. 2015; BoardSource 2017). For example, a 2018 study of UK charities found that two-thirds of the trustees (almost 6,400) of the top 500 charities by income are male; less than $7 \%$ are racial/ethnic minorities; $62 \%$ of boards are all white; and almost $80 \%$ of the leadership teams lack any racialized people (Inclusive Boards 2018). Although Oxfam indicates it recruits widely and the 14 member governing board of Oxfam GB at the time of the Haiti scandal had gender parity, it was still predominantly white (almost $80 \%$ ) and its senior leadership team lacked anyone form an ethnic minority (McVeigh 2018).

In many nonprofits, particularly small ones, the potential for weaknesses in governance and risk management is compounded by lack of understanding of and skills in risk management. A 2018 survey of small to medium-sized UK charities (assets under $£ 500,000$ ) found that $60 \%$ had had no risk training, and almost half were not confident in their ability to identify and assess risk (Policy Bee and University of Suffolk 2018). Better training and development for boards is seen as key remedies: the challenge being that almost $50 \%$ of charities have no budget for board development (House of Lords 2017). More effective self-regulation is also important, but these mechanisms must enable actors to disclose weaknesses without fear of punishment and need to be used as a means of learning for self-improvement (Crack 2018).

\subsection{Lack of Public Awareness}

These factors play out in a context in which the general public has a stunning lack of awareness of the nonprofit sector. This creates a small class of a select few 'premium' brands, and a relatively unknown mass of others. There is remarkable consistency in the nonprofit brands that are known and favored. For instance, when Americans were asked to name the one nonprofit they would support if they could support only one, over half chose one of only 20 organizations, with just five brands - all very large nonprofits - accounting for more than a third of the top organizations (Grey Matter Research 2018).

The observation by Maor, Gilad and Bloom $(2013,582)$ that an organization with a strong reputation and a wide span of affective social trust "can afford to keep silent, since most criticism will not tarnish that reputation" seems to apply to Oxfam GB, which is ranked as the 7th top charity brand in the UK (Hickman 2019). 
While in the immediate aftermath of the media flurry, public donations and trust plummeted, with a loss of 20,000 regular givers and £3.8million in public donations (Cooney 2019a, 2019b), support for Oxfam GB had bounced back a year later (Scurlock, Dolsak, and Prakash 2019). The other INGOS that were caught up in sexual abuse and exploitation were also global brands, and such globalness seems to afford them a special status, or at least the sense of special status (Laidler-Kylander, Quelch, and Simonin 2007), so that they, too, could withstand some very bad press in a way that lesser known nonprofits might not. There is an important caveat to this, however: should future incidents of poor behavior become assimilated to a loss of character, rather than capability, character reputation is likely to be much more difficult to repair (Mishina, Block, and Mannor 2012).

\subsection{Gaps in Regulation}

Finally, the scandals have exposed shortcomings in state and self-regulation - gaps that are not distinctive to England or the INGO subsector. The first pertains to the mandate, capacity and credibility of the state regulator. Even though Oxfam GB had informed the regulator of the incidents in Haiti shortly after they occurred, albeit not in a full and frank manner, the Charity Commission was slow to act or request additional information. When in 2015 it registered concerns about safeguarding practices that Oxfam GB committed to resolving, there was little follow-through - either to fix them or to ensure they had been fixed. By its own account, the Charity Commission was stretched in its mandate to oversee 168,000 charities (Anders 2018; House of Commons 2018), in large part because since 2010 its budget was cut by $40 \%$ and then frozen, resulting in criticism from the National Accounting Office that it did not put enough emphasis on investigating wrongdoing (NAO 2013; Breen 2018). Maintaining the credibility of the regulator with the sector it regulates is also important, and this, too, has been compromised in recent years. There is a growing critique that the Charity Commission has become more concerned with the public's perceptions of charities, particularly with information on compensation rates and overhead ratios, rather than providing an objective interpretation of charity law and the regulatory framework (Kennedy 2019). The effects of a compromised charity regulator are not unique to England and serve as a cautionary tale for other jurisdictions, including the US, Australia and Canada where the capacity and/or legitimacy of the regulatory body has also been diminished in recent years (McGregor-Lowndes and Wyatt 2017; Phillips in press).

The second issue relates to the kind of mandatory data collected, its use in risk management by the regulator and the perceived value to charities in providing it. As part of their annual reports to the Commission, charity trustees must indicate any "serious" incidents of wrongdoing, including financial loss or harm to their beneficiaries, their work or their reputations. However, the charities most at risk of such incidents seem unlikely to report: only $1.5 \%$ of charities filed a serious incident report for the five years before the Oxfam scandal, although the number of such reports rose by almost a third to over 2,800 in the year following (Kay 2019). The challenge is to ensure that charities see such reporting not merely as compliance but as a means of empowering their trustees and staff to monitor, come forward and investigate such incidents. The regulator needs effective data systems and risk assessment to identify under-reporting, and the capacity to investigate and sanction when required. Beyond incident reporting, charity regulators need to ensure they are asking the right questions that address good stewardship, recognizing that identifying the right questions suitable for such a diverse sector is not easy (Breen 2018; Brody 2012). In addition, although the work of the charitable sector has become increasingly globalized, regulators are still constrained by their geographical mandates, confined to overseeing those registered in their own jurisdictions without adequate means of information sharing. Particularly in the regulation of global INGOs, the need for greater cross-jurisdiction coordination is imperative.

Finally, sector self-regulation under-performed. While government charity regulators have an important role in setting standards, mandating reporting and sanctioning noncompliance, they are ill-suited, to providing adequate oversight of what emerged as the central problems in the Oxfam GB and related cases - internal governance, risk management, difficult cultures and lack of 'moral' leadership. Although a variety of accountability clubs exist in the global humanitarian aid sector, as in the nonprofit sector as a whole, most function as voluntary codes without monitoring of adherence or means of collective peer-to-peer learning. Consequently, many are criticized for being mainly symbolic, with participation aimed at satisfying the requirements of major funders (Hammad and Morton 2011; Barnett 2016; Tremblay-Boire, Prakash, and Gugerty 2016).

A stronger accountability system will require more effective sector self-regulation and closer integration of self- with state regulation. Given the weakness of voluntary codes and evidence that more formal accreditation enhances nonprofit reputation (Feng, Neely, and Slatten 2016; Peng, Kim, and Deat 2019) and is associated with reporting on impact, not just compliance with standards (Dougherty 2019), the sector needs to be more assertive in implementing certification systems that promote continuous improvement. One of the more rigorous mechanisms is the Canadian Standards Program which, while voluntary, involves certification based on peer-assessment and monitoring of compliance with 73 standards (scaled by organizational size) covering board governance, financial management, transparency, fundraising and staff and volunteer management. In 
addition, state regulatory processes could more effectively integrate such certification, for instance, by using accreditation as part of risk profiling of charities (Gulbrandsen 2014).

\section{Conclusion: Putting Humpty Together Again}

Theories of reputation management posit that organizations will play to different audiences, tailoring the extent and content of their information, including in response to crises, to stakeholders that are more important. The information disclosed should lead to enhanced perceptions of effectiveness and stakeholder trust, thus bringing positive benefits in the form of donations, contracts and other forms of support. The literature also recognizes that some deviations may occur: information is not disclosed, is shallow or is not used in a rational manner by stakeholders, and positive reputations for large, highly visible organizations tend to be durable, making them more damage resistant. More is at play in the Oxfam and related cases, however, than a few of these aberrations in the normal process of reputation management. This article argues that several factors that have become embedded in the nonprofit environment put unduly strong pressures on reputation management, encouraging limited transparency and protection of organizational reputation over mission and public benefit. These include: pressures for results and value for money that make it difficult to disclose missteps or admit failure; expectations that administrative costs will be kept very low that lead to an underinvestment in organizational infrastructure and accountability systems; and lack of diversity and inadequate training by governing boards that produce poor risk management and give rise to cultures in which staff and volunteers do not feel empowered to report abuses of power. These pressures are compounded by a general lack of public awareness of most nonprofits so that the public can be overlooked as legitimate stakeholders demanding of transparency, and the reputational durability of the large, highly visible nonprofits is reinforced.

Given that Oxfam GB seems to have recovered and restored its reputation, it is tempting to conclude that there is considerable tolerance for poor behavior and lack of transparency. Caution about presuming minimal long term effects is in order, however. In opinion surveys, the public consistently says that transparency matters to them, particularly knowing where the money goes and secondarily knowing the impact (YouGov and Killer Creative 2018). Increasingly, there is a clear message that charities need to pay attention to quality communication, not just superficial information in the interests of reputation protection, and the nonprofit sector can expect to be subject to increased scrutiny and critique. As one commentator said of the recent series of crises, "Not so long ago, criticising charity was a bit like spitting at granny ... You simply would not do it" (Hillier 2018). Not so any longer.

How do we repair this system of distorted incentives for the nonprofit sector as a whole? As a first step, state charity regulators need to be adequately resourced and credible - with charities, the rest of government and the public. Second, the information required from charities needs to be relevant and used in risk management by regulators. If more reporting is to be added, regulators will need to be strategic in what additional information can actually be used, and weigh the benefit against the costs to charities in an environment in which the public and funders expect low expenditures on administration. While specific questions about governance could be included in the annual reporting, as the US regulator does on the 990 form, such checklists necessarily under-estimate the diversity of (good) governance practices across the sector. The value of reporting of serious incidents needs to be apparent for charities, rather than perceived as rote accountability, but with proportionate sanctions for failing to report. For charities that work across borders, charity regulators need greater ability to share information and coordinate investigations.

Fundamentally, this series of scandals implicate nonprofit governance, and point to the need not only for the implementation of better safeguarding and control systems, but promotion of good governance, healthy, inclusive organizational cultures and strong leadership. State regulation is limited in its ability to affect good governance and organizational learning for improved practices so that robust sector self-regulation is essential, as is training for skills and leadership development. Voluntary codes will not be sufficient, and the sector will need to implement certification systems that promote learning, create incentives for self-improvement, have sufficient participation to be credible indicators of reputation with the public, and are integrated into risk management by state regulators. In addition, a culture of transparency needs to become the norm, reducing the presumption that selective and shallow disclosure is a smart tactic of reputation management. Governments, philanthropy and corporate partners will likely need to support the infrastructure for self-regulation, training and transparency, particularly for small charities.

We also need to dispel the overhead myth and the value for money concept used by funders that privileges efficiency over effectiveness and short term indicators over long term change. As long as the public and funders expect that charities should not spend very much on administrative costs - costs that build and maintain good governance systems and practices - they will be constrained in their ability to implement improved organi- 
zational governance and attend to the positive aspects of reputation management. Beyond making changes to safeguarding, or even fundamental reform in the aid sector, the Oxfam and other cases of abuse are an opportunity for the nonprofit sector as a whole, engaging with its funders, regulators and partners, to open wider conversations about reform of the dysfunctional aspects of the current working environment.

\section{Acknowledgements}

My appreciation to Aseem Prakash for organizing the panel on the Oxfam case at the 2018 ARNOVA conference that allowed me to develop my argument and for his insightful comments on drafts of this paper. I also benefited greatly from the ideas of the other panelists and participants at the ARNOVA panel and at the Reputation Symposium, Saïd Business School, University of Oxford. The insightful comments of the two anonymous referees greatly improved the paper.

\section{Notes}

1 Given that Oxfam GB and the other INGOs involved in misconduct are registered charities, this article refers to 'charities' (in a legal and regulatory sense), but interchangeability uses the label, 'nonprofit,' as is more common in the US literature.

2 Oxfam International also established an Independent Commission on Sexual Misconduct, Accountability and Culture Change to conduct a confederation-wide review of policies and practices, and its June 2019 report recommended extensive overall of the entire safeguarding system.

3 The analysis of media coverage focused on The Guardian, Third Sector and Civil Society (UK nonprofit 'trade' online publications), supplemented by international press when relevant and theses (e. g. Marques Dos Santos 2019). The main facts and themes were recorded and then compared and interpreted by the author.

4 In a 2018 report, the Independent Commission on Aid Impact, which scrutinizes aid spending in the UK, assessed the focus on value for money by the UK Department for International Development (DFID), noting that it tended to concentrate on controlling costs, efficient delivery and short-term results (ICAI 2018).

5 At about the same time, the world's largest community foundation, the Silicon Valley Community Foundation (California), was investigated for allegations of workplace harassment and bullying, with an independent report reaching the conclusion that "the growth of the organization took precedence over the well-being of staff members," producing a toxic culture (O'Leary, Hartnett, and Crowther 2018). In early 2019, a review of the organizational culture at Amnesty International found that $39 \%$ of its staff reported physical or mental health issues as a direct result of working there, and that the organization's "efforts to support staff wellbeing have been ad hoc, reactive and piecemeal" (Konterra 2019: 20).

6 In his critique of the Charity Commission's report, Purkis (2019) argues that the idea that there is a single culture in a decentralized, complex organization such as Oxfam is mythical. He also notes that at the time, Oxfam was going through an ambitious restructuring to create Oxfam International (that would upload some responsibilities for safeguarding from the affiliates to it), which greatly taxed unrestricted funds as well as the attention of senior staff and trustees at Oxfam GB.

\section{References}

Anders, M. 2018. “Did Budget Cuts at the Charity Commission Play a Role in the Safeguarding Crisis?” Devex, 31 May. Accessed March 18, 2019. https://www.devex.com/news/did-budget-cuts-at-the-charity-commission-play-a-role-in-the-safeguarding-crisis-92763.

Anderson, W. 2018. Written evidence submitted by William Anderson (SEA 0037), House of Commons, International Development Committee, Sexual exploitation and abuse in the aid sector, Eighth report of session 2017-19. London, UK: House of Commons.

Archambeault, D. S., and S. Webber. 2018. "Fraud Survival in Nonprofit Organizations: Empirical Evidence." Nonprofit Management \& Leadership 29: 29-46. https://doi.org/10.1002/nml.21313.

Arpan, L. M., and D. R. Roskos-Ewoldsen. 2005. "Stealing Thunder: Analysis of the Effects of Proactive Disclosure of Crisis Information." Public Relations Review 31: 425-33. https://doi.org/10.1016/j.pubrev.2005.05.003.

Auger, G. A. 2014. "Trust Me, Trust Me Not: An Experimental Analysis of the Effect of Transparency on Organizations." Journal of Public Relations Research 26 (4): 325-43. https://doi.org/10.1080/1062726X.2014.908722.

Bagwell, S., L. de Las Casas, M. van Poortvliet, and R. Abercrombie. 2013. Money for Cood: Understanding Donor Motivation and Behaviour. London: NPC.

Barnett, M. 2016. “Accountability and Global Governance: The View from Paternalism.” Regulation and Covernance 10: 134-48. https://doi.org/10.1111/rego.12083.

Becker, A. 2018. "An Experimental Study of Voluntary Nonprofit Accountability and Effects on Public Trust, Reputation, Perceived Quality, and Donation Behavior." Nonprofit and Voluntary Sector Quarterly 47 (3): 562-82. https://doi.org/10.1177/0899764018756200.

Bekkers, R. 2003. “Trust, Accreditation, and Philanthropy in the Netherlands.” Nonprofit and Voluntary Sector Quarterly 32 (4): 596-615. https://doi.org/10.1177/0899764003258102.

Berghmans, M., M. Simons, and J. Vandenabeele. 2017. “What Is Negotiated in Negotiated Accountability? the Case of INCOs." Voluntas 28 (4): 1529-61. https://doi.org/10.1007/s11266-016-9759-3.

BoardSource. 2017. Leading with Intent: 2017 National Index of Nonprofit Board Practices. Washington, DC: BoardSource.

Bond. 2012. Value for Money: What It Means for UK NCOs. London: Bond for International Development. 
Bond. 2014. Transparency Review: 2014 Pilot Cohort Report. London: Bond for International Development.

Breen, O. B. 2018. "Redeining the Measure of Success: A Historical and Comparative Look at Charity Regulation." In Research Handbook on Not-for-Profit Law, edited by M. Harding, 549-69. Cheltenham: Edward Elgar.

Brody, E. 2012. "Sunshine and Shadows on Charity Covernance: Public Disclosure as a Regulatory Tool." Florida Tax Review 12 (4): $183-234$.

Bryant, C. 2007. "Evaluation and Accountability in Emergency Relief." In Clobal Accountabilities: Participation, Pluralism and Public Ethics, edited by A Ebrahim, and E Weisband, 193-224. Cambridge: Cambridge University Press.

Bush, S. S. 2015. The Taming of Democracy Assistance: Why Democracy Promotion Does Not Confront Dictators. Cambridge: Cambridge University Press.

Busuioc, E. M., and M. Lodge. 2016. “The Reputational Basis of Public Accountability.” Covernance 29 (2): 247-63. https://doi.org/10.1111/gove.12161.

Busuioc, M., and M. Lodge. 2017. "Reputation and Accountability Relationships: Managing Accountability Expectations through Reputation." Public Administration Review 77 (1): 91-100. https://doi.org/10.1111/puar.12612.

Carpenter, D. P., and G. A. Krause. 2012. "Reputation and Public Administration." Public Administration Review 72 (1): $26-32$. https://doi.org/10.1111/j.1540-6210.2011.02506.x.

Charity Commission for England and Wales. 2019a. Statement of the Results of an Inquiry, Oxfam. London: CCEW.

Charity Commission for England and Wales. 2019b. Inquiry Report: Summary Findings and Conclusions, Oxfam. London: CCEW.

Christensen, T., and M. Lodge. 2018. "Reputation Management in Societal Security: A Comparative Study." American Review of Public Administration 72 (1): 26-32. https://doi.org/10.1177/0275074016670030.

Cnaan, R. A., K. Jones, A. Dickin, and M. Salomon. 2011. “Nonprofit Watchdogs: Do They Serve the Average Donor?” Nonprofit Management $\delta$ Leadership 21 (4): 381-97. https://doi.org/10.1002/nml.20032.

Coombs, W. T. 2007. "Protecting Organization Reputations during a Crisis: The Development and Application of Situational Crisis Communication Theory." Corporate Reputation Review 10 (3): 163-79. https://doi.org/10.1057/palgrave.crr.1550049.

Cooney, R. 2019a “All Our Major Donors Stood by Us during Crisis, Says Oxfam Director", Third Sector, 22 January. Accessed May 4, 2019. https://www.thirdsector.co.uk/major-donors-stood-us-during-crisis-says-oxfam-director/fundraising/article/1523543.

Cooney, R. 2019b. “One Year on from the Oxfam Scandal”, Third Sector, 11 February. Accessed March 15, 2019. https://www.thirdsector.co.uk/rebecca-cooney-one-year-oxfam-scandal/management/article/1525382.

Cordery, C. J., and R. F. Baskerville. 2011. “Charity Transgressions, Trust and Accountability.” Voluntas 22: 197-213. https://doi.org/10.1007/s11266-010-9132-x.

Coupet, J., and ]. L. Berrett. 2019. "Toward a Valid Approach to Nonprofit Efficiency Measurement." Nonprofit Mangement \& Leadership 29 (3): 299-320. https://doi.org/10.1002/nml.21336.

Crack, A. M. 2016. “Reversing the Telescope: Evaluating NCO Peer Regulation Initiatives." Journal of International Development 28 (1): 40-56. https://doi.org/10.1002/jid.3010.

Crack, A. M. 2018. “The Regulation of International NCOS: Assessing the Effectiveness of the INCO Accountability Charter." Voluntas 29 (2): 419-29. https://doi.org/10.1007/s11266-017-9866-9.

Deloffre, M. Z., and H. P. Schmitz. 2019. "INCO Legitimacy: Challenges and Responses." In Routledge Handbook of NCOs and International Relations, edited by T. Davies, 606-20. London: Routledge.

Dougherty, C. N. 2019. "Trust and Transparency: Accreditation and Impact Reporting by Canadian Charities." Canadian Journal of Nonprofit and Social Economy Research 10 (1): 6-25.

Farwell, M. M., M. L. Shier, and F. Handy. 2019. “Explaining Trust in Canadian Charities: The Influence of Public Perceptions of Accountability, Transparency, Familiarity and Institutional Trust." Voluntas 30: 768-82. https://doi.org/10.1007/s11266-018-00046-8.

Feng, N. C., D. G. Neely, and L. A. D. Slatten. 2016. “Accountability Standards for Nonprofit Organizations: Do Organizations Benefit from Certification Programs." International Journal of Public Administration 39 (6): 470-79. https://doi.org/10.1080/01900692.2015.1023444.

Fox, J. 2007. "The Uncertain Relationship between Transparency and Accountability." Development in Practice 17 (4-5): 663-71. https://doi.org/10.1080/09614520701469955.

Fredette, C., and R. S. Bernstein. 2019. "Ethno-racial Diversity on Nonprofit Boards: A Critical Mass Perspective." Nonprofit and Voluntary Sector Quarterly 48 (5): 931-52. https://doi.org/10.1177/0899764019839778.

Fung, A., M. Graham, and D. Weil. 2007. Full Disclosure: The Perils and Promises of Transparency. Cambridge, UK: Cambridge University Press.

Gneezy, U., E. A. Keenan, and A. Cneezy. 2014. “Avoiding Overhead Aversion in Charity.” Science 346: 632-35.

Gordon, T. P., C. L. Knock, and D. G. Neely. 2009. "The Role of Rating Agencies in the Market for Charitable Contributions: An Empirical Test." Journal of Accounting and Public Policy 28: 469-84. https://doi.org/10.1016/j.jaccpubpol.2009.08.001.

Gregory, A. G., and D. Howard. 2009. “The Nonprofit Starvation Cycle.” Stanford Social Innovation Review 7 (4): 49-53.

Grey Matter Research. 2018. The Donor Mindset Study Vi. Phoenix, AZ: Grey Matter. Accessed March 16, 2019. https://www.greymatterresearch.com/index_files/Cenerosity.htm.

Gugerty, M. K. 2009. “Signaling Virtue: Voluntary Accountability Programs among Nonprofit Organizations.” Policy Sciences 42: 243-73. https://doi.org/10.1007/s11077-009-9085-3.

Gulbrandsen, L. H. 2014. “Dynamic Covernance Interactions: Evolutionary Effects of State Responses to Non-State Certification Programs." Regulation \& Goverance 8: 74-92. https://doi.org/10.1111/rego.12005.

Hager, M. A., T. Pollak, K. Wing, and P. M. Rooney. 2004. Cetting What We Pay For: Low Overhead Limits Nonprofit Effectiveness (Nonprofit Overhead Cost Project, Brief No. 3). Washington, DC: Urban Institute.

Hammad, L., and B. Morton. 2011. Greater Influence, Greater Responsibility: Are INGOs' Self-regulatory Accountability Standards Effective? Ottawa: North South Institute.

Harold, J. 2014. "Moving from the Overhead Myth to an Overhead Solution: Next Steps." Philanthropy News Digest, 31 October. Accessed March 12, 2019. https://philanthropynewsdigest.org/commentary-and-opinion/moving-from-the-overhead-myth-to-an-overheadsolution-next-steps. 
Harris, E. E., and D. Neely. 2018. “Determinants and Consequences of Nonprofit Transparency." Journal of Accounting, Auditing \& Finance, Online First: 1-26. https://doi.org/10.1177/0148558X18814134.

Harris, E. E., C. Petrovits, and M. H. Yetman. 2018. “Maintaining Public Trust: The Influence of Transparency and Accountability on Donor Response to Fraud." Social Science Research Network. https://ssrn.com/abstract=3021543.

Hickman, A. 2019. “Oxfam Scandal Wiped Out £400m from Brand Valuation, Report Reveals.” PR Week, 9 January. Accessed May 8, 2019. https://www.prweek.com/article/1522440/oxfam-sex-scandal-wiped-40om-brand-valuation-report-reveals.

Hillier, A. 2018. “Oxfam: the Scandal that Kept on Running." Third Sector, 16 March. Accessed March 12, 2019. https://www.thirdsector.co.uk/oxfam-scandal-kept-running/article/1459728.

House of Commons, International Development Committee, UK. 2018. Sexual Exploitation and Abuse in the Aid Sector, Eighth Report of Session 2017-19. London: House of Commons.

House of Lords, Select Committee on Charities, UK. 2017. Stronger Charities for a Stronger Society, HL Paper 133. London: House of Lords.

Hyndman, N., and D. M. McConville. 2016. “Transparency in Reporting on Charities' Efficiency: A Framework for Analysis." Nonprofit and Voluntary Sector Quarterly 45 (4): 844-65. https://doi.org/10.1177/0899764015603205.

ICAI - Independent Commission for Aid impact. 2018. DFID's Approach to Value for Money in Programme and Portfolio Management. London: ICAI. Accessed October 9, 2019. https://icai.independent.gov.uk/html-report/dfids-approach-to-value-for-money-in-programme-andportfolio-management/.

Inclusive Boards. 2018. Charities: Inclusive Governance. London: Inclusive Boards.

Independent Commission on Sexual Misconduct, Accountability and Culture Change. 2019. Listening to People - Rebuilding Trust, Interim Report. Oxford: High Level Commission on Safeguarding, Sexual Misconduct, Accountability and Culture Change at Oxfam.

Kay, L. 2019. “Serious Incident Reports to Regulator Increase by Nearly a Third." Third Sector, 29 January. Accessed March 13, 2019. https://www.thirdsector.co.uk/serious-incident-reports-regulator-increase-nearly-third/governance/article/1524171.

Keating, V. C., and E. Thrandardottir. 2017. "NCOs, Trust, and the Accountability Agenda." British Journal of Politics and International Relations 19 (1): 134-51. https://doi.org/10.1177/1369148116682655.

Kennedy, J. 2019. "The Charity Commission Is Losing the 'trust and Confidence' of Charities." Directory of Social Change, 9 October. Accessed October 11, 2019. https://www.dsc.org.uk/content/the-charity-commission-is-losing-the-trust-and-confidence-of-charities/\#.

Konterra Group. 2019. Amnesty International Staff Wellbeing Review. Washington, DC: Konterra Group.

Laidler-Kylander, N., J. A. Quelch, and B. L. Simonin. 2007. "Building and Valuing Clobal Brands in the Nonprofit Sector." Nonprofit Management and Leadership 17 (3): 253-77. https://doi.org/10.1002/nml.149.

Lange, D., P. M. Lee, and Y. Dai. 2011. “Organizational Reputation: A Review.” Journal of Management 37 (1): 153-84. https://doi.org/10.1177/0149206310390963.

Lecy, J. D., and E. A. M. Searing. 2015. "Anatomy of the Nonprofit Starvation Cycle: An Analysis of Falling Overhead Ratios in the Nonprofit Sector." Nonprofit and Voluntary Sector Quarterly 44 (3): 539-63. https://doi.org/10.1177/0899764014527175.

Maor, M., S. Gilad, and P. B. N. Bloom. 2013. "Organizational Reputation, Regulatory Talk, and Strategic Silence." Journal of Public Administration Research and Theory 23 (1): 581-608. https://doi.org/10.1093/jopart/mus047.

Marques Dos Santos, M. 2019. "How organizations address legitimacy issues: The case of Oxfam." MSc thesis, Lisbon, Portugal: Business Administration, Católica-Lisbon School of Business and Economics.

Mazurana, D., and P. Donnelly. 2017. Stop the Sexual Assault against Humanitarian and Development Aid Workers. Somerville, MA: Feinstein International Center, Tufts Univeristy.

McDonnell, D., and A. C. Rutherford. 2018. “Promoting Charity Accountability: Understanding Disclosure of Serious Incidents.” Accounting Forum. https://doi.org/10.1016/j.accfor.2018.05.003.

McGregor-Lowndes, M., and B. Wyatt. 2017. “Introduction." In Regulating Charities: The Inside Story, edited by M. McGregor-Lowndes, and B. Wyatt, 1-14. London: Routledge.

McVeigh, K. 2018. “Where's the Diversity among Charity Trustees, Asks Critical Report.” The Cuardian, 19 April. Accessed October 11, 2019. https://www.theguardian.com/global-development/2018/apr/19/alarming-lack-diversity-charity-trustees-england-wales.

Meer, ]. 2017. “Are Overhead Costs a Good Guide for Charitable Giving?” IZA World of Labor, 1-10. Accessed March 16, 2019. https://wol.iza.org/articles/are-overhead-costs-good-guide-for-charitable-giving/long.

Mishina, Y., E. S. Block, and M. J. Mannor. 2012. "The Path Dependence of Organizational Reputation: How Social Judgment Influences Assessments of Capability and Character." Strategic Management Journal 33: 359-477. https://doi.org/10.1002/smj.958.

Mitchell, G. E. 2014. "Creating a Philanthropic Marketplace through Accounting, Disclosure, and Intermediation." Public Performance \& Management Review 38 (1): 23-47. https://doi.org/10.2753/PMR1530-9576380102.

Mitchell, G. E. 2015. "The Attributes of Effective NCOs and the Leadership Values Associated with a Reputation for Organizational Effectiveness." Nonprofit Management and Leadership 26 (1): 39-51. https://doi.org/10.1002/nml.21143.

Mitchell, G. E., and S. S. Stroup. 2017. "The Reputation of NGOs: Peer Evaluatons of Effectiveness." Review of International Organizations 12: 397-419. https://doi.org/10.1007/s11558-016-9259-7.

Muttart Foundation. 2013. Talking with Canadians. Edmonton, AB: Muttart Foundation.

NAO - National Accounting Office. 2013. Report by the Comptroller and Auditor Ceneral: The Regulatory Effectiveness of the Charity Commission. London: NAO.

O'Leary, A., K. Hartnett, and R. Crowther. 2018. Public Report on Workplace Investibation. Palo Alto, CA: Boies,Schiller, Flexner LLP.

Oxfam. 2018. Annual Report and Accounts 2017/18. Oxford: Oxfam.

Peng, S., M. Kim, and F. Deat. 2019. “The Effects of Nonprofit Reputation on Charitable Giving: A Survey Experiment.” Voluntas 30: 811-27. https://doi.org/10.1007/s11266-019-00130-7.

Pfarrer, M. D., K. A. Decelles, K. G. Smith, and M. S. Taylor. 2008. “After the Fall: Reintegrating the Corrupt Organization.” Academy ofManagement Review 33 (3): 730-59. https://doi.org/10.2307/20159433.

Phillips, S. D. (in press). "A Changing Management Context: the US, UK, Canada and Australia." In Routledge Companion to Nonprofit Management, edited by H. K. Anheier, and S. Toepler. London: Routledge. 
Policy Bee and University of Suffolk. 2018. Under the Radar: Risk Management in Small Charities. Ipswich, UK: Suffolk Institute for Social and Economic Research, University of Suffolk.

Populus and Charity Commission. 2018. Trust in Charities, 2018. London: Charity Commission of England and Wales.

Potoski, M., and A. Prakash. 2013. "Creen Clubs: Collective Action and Voluntary Environmental Programs." Annual Review of Political Science 16 (1): 399-419. https://doi.org/10.1146/annurev-polisci-032211-211224.

Prakash, A., and M. K. Gugerty. 2010. "Trust but Verify? Voluntary Regulation Programs in the Nonprofit Sector." Regulation and Covernance 4 (1): 22-47. https://doi.org/10.1111/j.1748-5991.2009.01067.x.

Prakash, A., and M. Potoski. 2007. "Collective Action through Voluntary Environmental Programs: A Club Theory Perspective." Policy Studies Journal 35 (4): 773-92. https://doi.org/10.1111/j.1541-0072.2007.00247.x.

Purkis, A. 2019. "Rough Justice: The Charity Commission and Oxfam." Directory of Social Change, 3 October. Accessed October 8, 2019. https://www.dsc.org.uk/content/rough-justice-the-charity-commission-and-oxfam/.

Rousseau, D. M., S. B Sitkin, R. S. Burt, and C. Camerer. 1998. "Not so Different after All: A Cross-discipline View of Trust." Academy of Management Review 23 (3): 393-404.

Sargeant, A., and S. Lee. 2004. "Donor Trust and Relationship Commitment in the U.K. Charity Sector: The Impact on Behavior." Nonprofit and Voluntary Secctor Quarterly 33 (2): 185-202.

Sarstedt, M., and P. Schloderer. 2010. “Developing a Measurement Approach for Reputation of Non-profit Organizations." Journal of Nonprofit and Voluntary Sector Marketing 15: 276-99.

Saxton, G. D., J-S. Kuo, and Y-C. Ho. 2012. "The Determinants of Voluntary Financial Disclosure by Nonprofit Organizations." Nonprofit and Voluntary Sector Quarterly 41 (6): 1051-71. https://doi.org/10.1177/0899764011427597.

Schleifer, P., M. Fiorini, and C. Auld. 2019. "Transparency in Transnational Covernance: The Determinants of Information Disclosure of Voluntary Sustainability Programs." Regulation \& Covernance, 28 February. https://doi.org/10.1111/rego.12241.

Schubert, P., and S. Boenigk. 2019. "The Nonprofit Starvation Cycle: Empirical Evidence from a Cerman Context." Nonprofit and Voluntary Sector Quarterly, 24 January. https://doi.org/10.1177/0899764018824669.

Scurlock, R., N. Dolsak, and A. Prakash. 2019. “Recovering from Scandals: Twitter Coverage of Oxfam and Save the Children Scandals.” Voluntas, Online First, August. https://doi.org/10.1007/s11266-019-00148-x.

Sloan, M. F. 2009. "The Effects of Nonprofit Donor Behavior." Nonprofit and Voluntary Sector Quarterly 38 (2): 20-236.

Striebing, C. 2017. “Professionalization and Voluntary Transparency Practices in Nonprofit Organizations." Nonprofit Management \& Leadership 38 (1): 65-83. https://doi.org/10.1002/nml.

Szper, R., and A. Prakash. 2011. "Charity Watchdogs and the Limits of Information-Based Regulation." Voluntas 22 (1): 112-41. https://doi.org/10.1007/s11266-010-9156-2.

Tremblay-Boire, J., and A. Prakash. 2015. “Accountability.org: Online Disclosure by US Nonprofits.” Voluntas 26: 693-719. https://doi.org/10.1007/s11266-014-9452-3.

Tremblay-Boire, J., A. Prakash, and M. K. Gugerty. 2016. “Regulation by Reputation: Monitoring and Sanctioning in Nonprofit Accountability Clubs." Public Administration Review 76 (5): 712-22. https://doi.org/10.1111/puar.12539.

Weakley, K. 2018. “We Didn't Work Hard Enough on Cultlure Change." Civil Society, 29 March. Accessed October 1, 2019. https://www.civilsociety.co.uk/news/we-didn-t-work-hard-enough-on-culture-change-says-oxfam-chair.html.

Weil, D., A. Fung, M. Graham, E. Fagotto, et al. 2005. "The effectiveness of regulatory disclosure policies." Journal of Policy Analysis and Management 25 (1): 155-81. DOI: https://doi.org/10.1002/pam.20160.

Weisinger, J. Y., R. Borges-Méndez, and C. Milofsky. 2015. “Diversity in the Nonprofit and Voluntary Sector." Nonprofit and Voluntary Sector Quarterly 45 (1_suppl): 3S-27S. https://doi.org/10.1177/0899764015613568.

Willems, J., S. Boenigk, and M. Jegers. 2014. “Seven Trade-offs in Measuring Nonprofit Performance and Effectiveness." Voluntas 25 (6): 1648 70.

Willems, J., and L. Faulk. 2019. “Does Voluntary Disclosure Matter When Organizations Violate Stakeholder Trust?” Journal of Behavioral Public Administration 2 (1): 1-16. https://doi.org/10.30636/jbpa.21.45.

Willems, J., M. Jegers, and L. Faulk. 2016. "Organizational Effectiveness Reputation in the Nonprofit Sector." Public Performance and Management Review 39 (2): 454-75. https://doi.org/10.1080/15309576.2015.1108802.

Willems, J., C. J. Waldner, Y. I. Dere, Y. Matsuo, and K. Högy. 2017. “The Role of Formal Third-Party Endorsements and Informal Self-Proclaiming Signals in Nonprofit Reputation Building." Nonprofit and Voluntary Sector Quarterly 46 (5): 1092-105. https://doi.org/10.1177/0899764017720770.

Willlems, ]., C. J. Waldner, and J. C. Ronquillo. 2019. “Reputaiton Star Society: Are Star Ratings Consulted as Substitute or Complementary Information?" Decision Support Systems 124 (September): 1-11. https://doi.org/10.1016/j.dss.2019.113080.

YouGov and Killer Creative. 2018. Love charity research 2018. Accessed March 12, 2019. https://lovecharity2018.com/. 